\title{
Management of Imatinib-Resistant CML Patients
}

\author{
Rolf Linke ${ }^{a}$ Wolfram Dempke ${ }^{a, b}$ \\ ${ }^{a}$ Bristol-Myers Squibb, Abteilung Onkologie, München, \\ ${ }^{\mathrm{b}}$ Klinikum Großhadern, Ludwig-Maximilians-Universität München, Germany
}

Key Words

$\mathrm{CML} \cdot$ Imatinib resistance $\cdot$ Mutations $\cdot$ Management

\section{Summary}

Imatinib has had marked impact on outcomes in chronic myelogenous leukemia (CML) patients for all stages of the disease and is endorsed by international treatment guidelines as the first line option. Although imatinib is highly effective and well tolerated, the development of resistance represents a clinical challenge. Since the most frequently identified mechanism of acquired imatinib resistance is bcr-abl kinase domain point mutations, periodic hematologic, cytogenetic, and molecular monitoring is critical throughout imatinib therapy. Once cytogenetic remission is achieved, residual disease can be monitored by bcr-abl transcript levels as assayed by reverse transcription polymerase chain reaction (RT-PCR). Detection of bcr-abl mutants prior to and during imatinib therapy can aid in risk stratification as well as in determining therapeutic strategies. Thus, mutation screening is indicated in patients lacking or losing hematologic response. Moreover, search for mutations should also be performed when a 3-log reduction of bcr-abl transcripts is not achieved or there is a reproducible increase of transcript levels. In patients harboring mutations which confer imatinib resistance, novel second line tyrosine kinase inhibitors have demonstrated encouraging efficacy with low toxicity. Only the T315I bcr-abl mutant has proved totally resistant to all clinically available bcr-abl inhibitors. Strategies to further increase the rates of complete molecular remissions represent the next frontier in the targeted therapy of CML patients.

\author{
Schlüsselwörter \\ CML · Imatinib-Resistenz · Mutationen · Management
}

\section{Zusammenfassung}

Die Einführung von Imatinib hat die Behandlung für CML-Patienten in allen Stadien der Erkrankung maßgeblich verbessert. Entsprechend wird Imatinib in internationalen Therapieempfehlungen als Standardtherapie für die Erstlinientherapie empfohlen. Trotz der guten Wirksamkeit und Verträglichkeit von Imatinib stellt die Resistenzentwicklung eine Herausforderung in der Praxis dar. Hauptmechanismus für die Entwicklung einer ImatinibResistenz sind Punktmutationen der bcr-abl-Kinasedomäne. Deshalb ist die regelmäßige Kontrolle des hämatologischen, zytogenetischen und molekularen Ansprechens unter einer Imatinibtherapie essentiell. Wenn eine zytogenetische Remission erreicht wurde, kann die Resterkrankung durch Bestimmung des bcr-abl-Transkript-Levels durch RT-PCR (reverse transcription polymerase chain reaction) überwacht werden. Die Identifikation von bcr-abl-Mutationen vor und während einer Imatinibtherapie kann dazu beitragen, die Risikostratifikation und die sich daraus ableitende Therapieentscheidung zu optimieren. Eine Mutationsanalyse ist angezeigt, wenn ein hämatologisches Ansprechen nicht erreicht wird bzw. verloren geht, wenn keine Abnahme der bcr-abl-Transkripte um 3-log erreicht wird oder ein reproduzierbarer Anstieg registriert wird. Bei Patienten mit Imatinib-Resistenz haben Tyrosinkinase-Inhibitoren der 2. Generation eine vielversprechende Wirksamkeit bei akzeptabler Toxizität gezeigt. Lediglich die T315l-bcr-abl-Mutation hat sich als resistent gegenüber allen bisher verfügbaren bcr-abl-Kinase-Inhibitoren erwiesen. Die Suche nach Strategien zur Verbesserung der Rate der kompletten molekularen Remission wird zukünftig im Fokus der zielgerichteten Therapie für CML-Patienten stehen.

\begin{tabular}{|c|c|}
\hline KARGER & (C) 2007 S. Karger GmbH, Freiburg \\
\hline $\begin{array}{l}\text { Fax +49 } 7614520714 \\
\text { E-mail Information@Karger.de } \\
\text { www.karger.com }\end{array}$ & $\begin{array}{l}\text { Accessible online at: } \\
\text { www.karger.com/onk }\end{array}$ \\
\hline
\end{tabular}

Dr. Dr. med. Wolfram Dempke

Bristol-Myers Squibb

Abteilung Onkologie

Sapporobogen 6-8, 80637 München, Germany

Tel. +49 89 12142-479, Fax -257

E-mail wolfram.dempke@bms.com 


\section{Introduction}

The past few decades have witnessed considerable advances in the understanding of the pathophysiology underlying many diseases. This knowledge has provided a platform for the development of targeted molecular therapies. Defining the molecular basis of many cancers has shifted the focus of research towards identifying compounds that specifically inhibit proteins involved in signal transduction within malignant cells. One of the best examples is the development of treatment strategies for chronic myeloid leukemia (CML), the first human malignant disease to be linked to an acquired genetic abnormality.

CML is a myeloproliferative disorder characterized by the expansion of a clone of hematopoietic cells that carries the Philadelphia $(\mathrm{Ph})$ chromosome. The $\mathrm{Ph}$ chromosome results from a reciprocal translocation between the long arms of chromosome 9 and 22: $\mathrm{t}(9 ; 22)(\mathrm{q} 34 ; \mathrm{q} 11)$. The molecular consequence of this translocation is the novel fusion gene bcr-abl which encodes a constitutively active tyrosine kinase (reviewed by [1]). The development of imatinib represented a major success for bcr-abl targeted therapy and a breakthrough in the management of CML. Before this, treatment options for CML had been limited, and interferon- $\alpha$ plus cytarabine was considered standard therapy for patients with CML who were not planning to undergo allogeneic stem cell transplantation (SCT). In the phase III IRIS trial, the efficacy of imatinib was compared with the combination of interferon- $\alpha$ and lowdose cytarabine in patients with newly chronic phase CML. The cumulative best rates of complete cytogenetic response among patients receiving imatinib were $87 \%$ by 60 months (cumulative complete hematologic response after 60 months: $98 \%$ ). An estimated 7\% of patients progressed to acceleratedphase CML or blast crisis, and the estimated overall survival of all patients who received imatinib as initial therapy was $89 \%$ at 60 months, which is higher than that reported in any previously published prospective study of the treatment of CML. Patients who had a complete cytogenetic response or in whom levels of bcr-abl transcripts had fallen by at least 3-log below a standardized baseline had a significantly lower risk of disease progression than did patients without a complete cytogenetic response $(p<0.001)$ [2]. The IRIS study data have established imatinib $(400 \mathrm{mg} / \mathrm{d})$ as the standard therapy for CML (fig. 1), and it is currently recommended that imatinib therapy is continued indefinitely since no evidence exists to support the belief that patients taking imatinib can safely discontinue therapy once they achieve a complete molecular response. Most patients who have discontinued imatinib therapy have rapidly experienced both molecular and cytogenetic relapse, even when some had sustained undetectable levels of bcr-abl transcripts for long periods [3]. However, in a study presented by Rousselot et al. [4], the discontinuation of imatinib in CML patients with undetectable residual disease for more than 2 years was investigated. $50 \%(6 / 12)$ of patients still

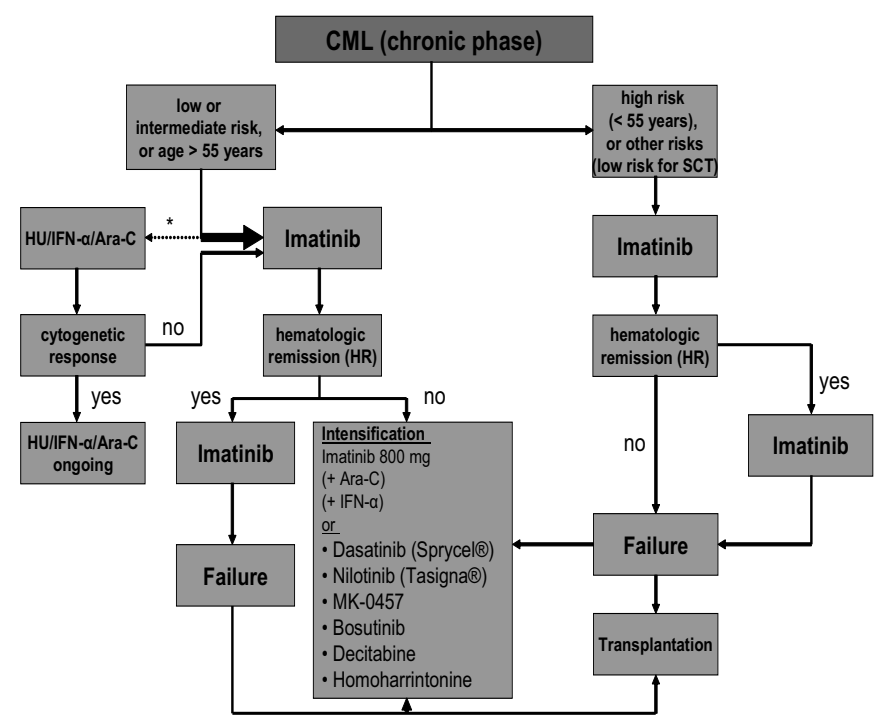

Fig. 1. Treatment algorithm for newly diagnosed CML patients in chronic phase.

*Only for patients with CML in early chronic phase (standard risk).

had an undetectable level of bcr-abl transcript after a medium follow-up of 18 months.

A subset of patients with CML will exhibit either primary or secondary resistance to imatinib. Primary resistance refers to patients never responding to imatinib, whereas secondary resistance occurs when a patient who had an initial response to imatinib eventually loses the response. Among patients treated in chronic phase CML, the rate of resistance has been estimated to be $1-5 \%$ /year with a decreasing frequency after 3 years [5] (table 1). Imatinib resistance among patients with CML is now a clinically significant problem and may limit the long-term benefits of the drug, particularly in advanced disease.

\section{Mechanisms of Imatinib Resistance}

Mechanisms of imatinib resistance have been intensively investigated after first cases of resistance were reported in the year 2000 [6]. To date, 5 mechanisms of imatinib resistance have been identified: i) bcr-abl gene mutations; ii) bcr-abl overexpression/amplification; iii) activation of bcr-abl independent kinase pathways; iv) binding to $\alpha 1$-acid glycoprotein in the plasma; v) increased expression of imatinib efflux and/or influx transporters.

\section{bcr-abl Gene Mutations}

Point mutations in the abl kinase domain are the most frequent mechanisms of acquired imatinib resistance in CML patients. Imatinib-resistant bcr-abl point mutations have been found to pre-exist in newly diagnosed CML patients as well as be acquired to selective pressure of imatinib. Mutations medi- 
Table 1. Primary and secondary resistance rates following imatinib treatment (400 mg/d) in CML patients (modified after [5])

\begin{tabular}{lcc}
\hline CML & $\begin{array}{l}\text { Primary } \\
\text { resistance, \% }\end{array}$ & $\begin{array}{l}\text { Secondary } \\
\text { resistance, \% }\end{array}$ \\
\hline Early chronic phase & 4 & 7 \\
Late chronic phase & 4 & 20 \\
Accelerated phase $^{\mathrm{a}}$ & 24 & 60 \\
Blast crisis $^{\mathrm{a}}$ & 66 & 93 \\
\hline
\end{tabular}

${ }^{\mathrm{a}}$ Imatinib $600 \mathrm{mg} /$ day.

ating imatinib resistance may occur at any time [7]. These mutations can be classified into 4 groups [8]: i) mutations which directly affect the imatinib binding site, e.g. T315I, F317L; ii) mutations within the ATP phosphate binding loop ( = P-loop, a highly conserved region responsible for phosphate binding), e.g. E255K, G250E, Q252H, Y253F/H; iii) mutations within the activation loop (resulting in activated confirmation of abl which is insensitive to imatinib), e.g. H396R; iv) mutations within the catalytic domain, e.g. E355G, F359V.

In accordance with the higher sensitivity of detection methods, the number of identified point mutation has been raised. To date, more than 73 point mutations have been isolated from imatinib-resistant CML patients. The biology of some of the different mutations, their prognosis impact, and their $\mathrm{IC}_{50}$ values are listed in table 2. Depending on the phase of the disease, the definition of resistance, and the detection method, the frequency of bcr-abl mutations in resistant patients was reported to be in the range of $42-90 \%$ [9]. Mutations are identified more frequently in CML patients in accelerated phase or blast crisis. Detection of bcr-abl mutations in CML patients treated with imatinib is virtually always accompanied by clinical resistance, and mutations in the P-loop are associated with a poor prognosis [10]. In most of the cases, only 1 mutation is identified at the beginning of resistance, while the proportion of patients with more than 1 kinase mutation is increasing during disease progression. Interestingly, it was reported by Shah et al. [11] that additional mutations identified in association with alternative tyrosine kinase inhibitors confer in some cases again sensitivity against imatinib. Not all mutations have the same clinical impact, and the relationship between imatinib resistance and the occurrence of point mutations in the bcr-abl domain is not clearly understood. The T315I mutation and some mutations of the P-loop of bcr-abl are associated with a greater level of resistance compared to others which might be overcome by a dose increase of imatinib or which are functionally irrelevant [12].

\section{bcr-abl Overexpression/Amplification}

Overexpression of the bcr-abl protein due to amplification of the corresponding gene was first observed in vitro when resis-
Table 2. Characterization of some bcr-abl mutations conferring imatinib resistance (modified after [7]. Examples of imatinib-resistant mutations that destabilize the inactive conformation are those that affect residues Glu255, Tyr253 and Gly250 in the P-loop of the abl kinase domain. However, many of these mutations are relatively rare, and the most common, affecting Gly250, Tyr253, Glu255, Thr315, Met351 and Phe359, account for $60-70 \%$ of all mutations [9]

\begin{tabular}{|c|c|c|c|}
\hline Mutation & $\begin{array}{l}\mathrm{IC}_{50} \text { Ima- } \\
\text { tinib }(\mathrm{nM})\end{array}$ & $\begin{array}{l}\text { Frequency } \\
\text { in pts. }\end{array}$ & Mechanism \\
\hline Wild type & 221 & NA & NA \\
\hline Leu248Val & 1,011 & high & $\begin{array}{l}\text { poorer topological fit } \\
\text { with imatinib }\end{array}$ \\
\hline Gly250Ala & 313 & high & unclear \\
\hline Gly250Glu & 2,287 & low/medium & no imatinib binding \\
\hline Gln252His & 1,080 & low/medium & $\begin{array}{l}\text { destabilization of } \\
\text { inactive state }\end{array}$ \\
\hline Tyr253His & $>10,000$ & high & $\begin{array}{l}\text { loss of } \pi-\pi \text { interaction } \\
\text { with imatinib }\end{array}$ \\
\hline Tyr253Phe & ND & high & $\begin{array}{l}\text { destabilization of } \\
\text { inactive state }\end{array}$ \\
\hline Tyr315Ile & $>10,000$ & high & $\begin{array}{r}\text { steric hindrance } \\
\text { (gate keeper) }\end{array}$ \\
\hline Phe317Leu & 797 & high & $\begin{array}{l}\text { poorer topological fit } \\
\text { with imatinib }\end{array}$ \\
\hline Phe317Val & 544 & low/medium & $\begin{array}{l}\text { poorer topological fit } \\
\text { with imatinib }\end{array}$ \\
\hline Met351Thr & 593 & high & unclear \\
\hline Glu355Gly & 601 & high & $\begin{array}{l}\text { no obvious reason for } \\
\text { resistance }\end{array}$ \\
\hline Phe359Val & 1,528 & high & $\begin{array}{l}\text { poorer topological fit } \\
\text { with inhibitor }\end{array}$ \\
\hline His396arg & ND & ND & $\begin{array}{l}\text { destabilization of } \\
\text { inactive state }\end{array}$ \\
\hline
\end{tabular}

$\mathrm{NA}=$ Not applicable ND $=$ not determined .

tant cell lines were generated by exposure to gradually increasing doses of imatinib. This phenomenon has been reported in relatively small proportion of patients, with an overall percentage of $18 \%$, but this may be an underestimate if its detection is only based on the cytogenetic findings of $\mathrm{Ph}$ chromosome duplication [8]. Overexpression of bcr-abl leads to resistance by increasing the amount of target protein needed to be inhibited by the therapeutic dose of the drug.

\section{Activation of bcr-abl Independent Kinase Pathways}

The src family kinases, Lyn and Hck, are activated in bcr-ablexpressing cell lines. Lyn is overexpressed and activated in an imatinib-resistant CML cell line generated by incubation of the parental line in increasing concentrations of imatinib and in samples from CML patients who were resistant to imatinib [13]. Lyn suppression by a src kinase inhibitor resulted in reduced proliferation and survival of the imatinib-resistant but not the sensitive cell line. Molecular analyses have shown that transcripts from genes with anti-apoptotic or malignant transformation properties and with involvement in signal transduc- 
tion/transcriptional regulation (e.g. mTOR, p53, GM-CSF) are overexpressed in CML cells innately resistant to imatinib, suggesting that pathways downstream of bcr-abl and independent of its kinase activity may be important factors for imatinib resistance [14].

\section{Binding to $\alpha 1$-acid Glycoprotein in Plasma}

Drug-binding proteins like $\alpha 1$-acid glycoprotein can capture imatinib in the plasma, which can result in reduced capability of imatinib to inhibit bcr-abl kinase activity. The relevance of this resistance mechanism, however, needs further investigations [15].

\section{Increased Expression of Imatinib Efflux and/or Influx}

Transporters

A well described mechanism of resistance in cancer therapy is P-glycoprotein (P-170), a MDR1 (multidrug resistance) gene product which is able to reduce the intracellular concentration of a variety of anticancer drugs by an energy (ATP)-dependent efflux. Imatinib and other tyrosine kinase inhibitors are substrates of P-170. It was shown that the intracellular concentration of imatinib is lower in P-170-expressing cells [16]. The clinical relevance of this mechanism for imatinib resistance has to be further evaluated. To date, P-170 overexpression in imatinib-resistant patients has not yet been reported. Nevertheless, adding P-170 inhibitors like verapamil to cultures of imatinib-resistant cell lines reduced colony formation of these cells, suggesting a significant role of P-170 overexpression in clinical imatinib resistance [17]. The breast cancer resistance protein (BCRP)/ABCG2, another drug efflux pump system, is overexpressed in a number of tumors including CML stem cells [18]. The human organic cation transporter 1 (hOCT1) mediates the active transportation of imatinib into cells. Inhibition or low expression of this transport system may constitute a poorer outcome [19].

It is interesting to note that in terms of gastrointestinal stromal tumors (GISTs) similar mechanisms of imatinib resistance have been identified. Primary resistance in almost all patients have tumors bearing either a c-kit mutation in exon 9, a D $842 \mathrm{~V}$ mutation in PDGFR- $\alpha$, or a wild-type genotype in both c-kit and PDGFR- $\alpha$. The most important event in GIST patients with secondary imatinib resistance is the occurrence of c-kit mutations next to the initial mutation (50-70\% of all patients). Secondary mutations predominantly occur in exons $13,14,17$, or 18 of the c-kit gene, all encoding regions in the vicinity of the ATP-binding site or the kinase activation loop of c-kit [20]. Furthermore, c-kit amplifications, increased drug efflux pumps, and increased levels of $\alpha 1$-acid glycoprotein have also been identified in imatinib-resistant GIST patients. For CML patients, methods for predicting and monitoring response to treatment have changed considerably in recent years. Since responses to imatinib may occur at hematologic, cytogenetic, and molecular levels, the proper follow-up of imatinib-treated patients is based on hematologic, cytogenetic,
Table 3. Response definitions in CML patients following imatinib treatment

Complete hematologic remission

Platelets $<450,000 / \mu 1$

White blood cell count $<10,000 / \mu \mathrm{l}$

Differential without immature granulocytes and less than $5 \%$ basophils No palpable spleen

Cytogenetic remission

Complete: $\mathrm{Ph}+0$

Partial: $\mathrm{Ph}+1-35 \%$

Minor: $\mathrm{Ph}+36-65 \%$

Minimal: $\mathrm{Ph}+66-95 \%$

None: $\mathrm{Ph}+>95 \%$

Molecular response

Complete: transcript non-quantifiable and non-detectable (standardized bcr-abl/abl ratio $<0.001 \%$ )

Major: standardized bcr-abl/abl ratio $<0.10 \%$

and molecular techniques. In the early phases of treatment, methods which detect residual $\mathrm{Ph}$-positive cells in the blood or bone marrow are most informative. Once $\mathrm{Ph}$ negativity is achieved, residual leukemia can best be monitored by quantitative reverse transcription polymerase chain reaction (RTPCR) assay which measures bcr-abl transcript levels and reflects the survival of a small number of leukemia cells. In table 3, the remission definitions are reported.

Recently, definitions of failure and suboptimal response have also been suggested [12]. Failure implies that the patient should be switched to other treatments whenever available. Suboptimal response implies that the patient may still have a substantial benefit from continuing imatinib treatment, but the long-term outcome is not likely to be optimal. Some warnings have been proposed to monitor patients very carefully, as shown in table 4.

\section{Clinical Management of Imatinib-Resistant Patients}

Complete cytogenetic response seems to be the most important response-relating prognostic factor according to the IRIS study. Given the high rates of complete cytogenetic response (CCyR) with imatinib, molecular monitoring of bcr-abl transcript levels with RT-PCR technology has become an important asset of long-term CML management, and it has emerged as the method of choice for monitoring residual disease in patients with CCyR. However, currently, there are various different methods in use for reporting results of RT-PCR data on individual patients making a reliable comparison of the data difficult. In an attempt to standardize data of detecting and measuring bcr-abl transcripts in CML patients of multiple 


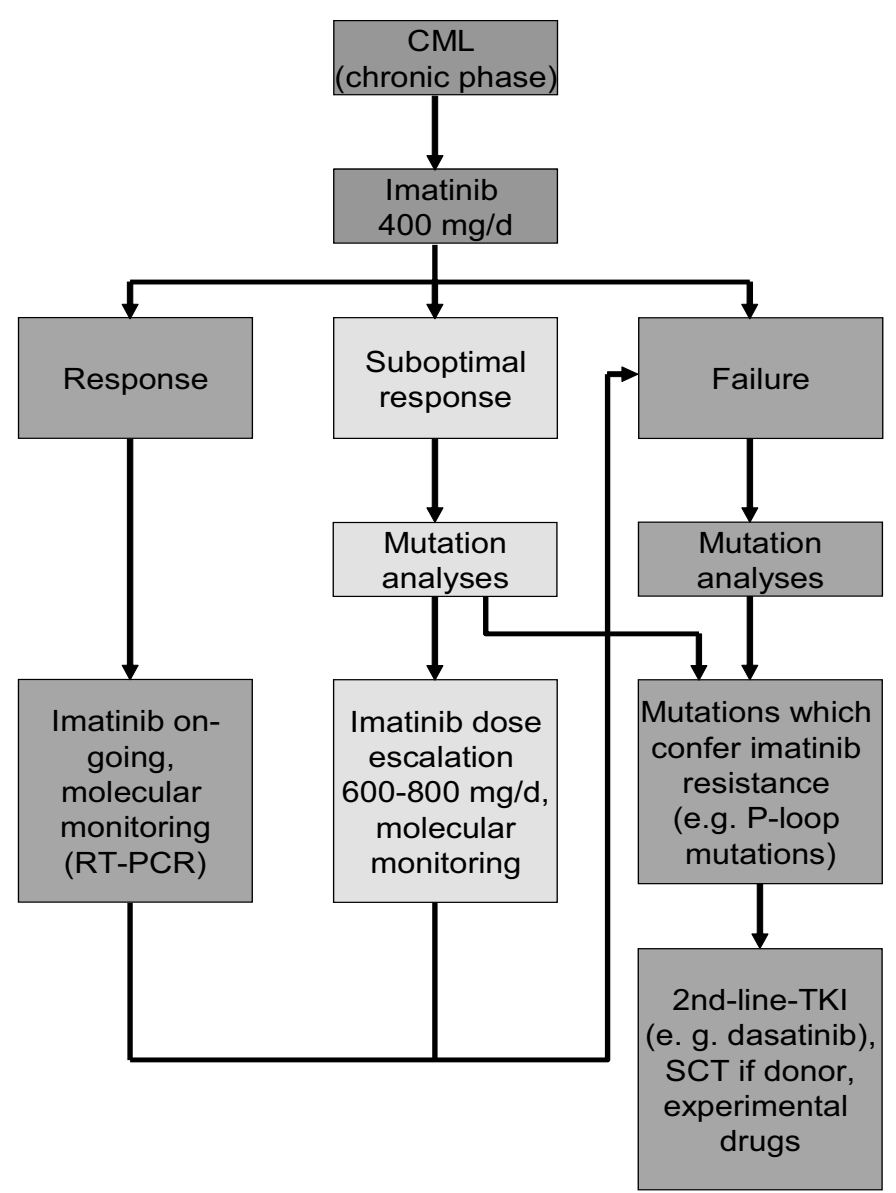

Fig. 2. Schema for the molecular monitoring of CML patients (TKI = tyrosine kinase inhibitor; $\mathrm{SCT}=$ stem cell transplantation).

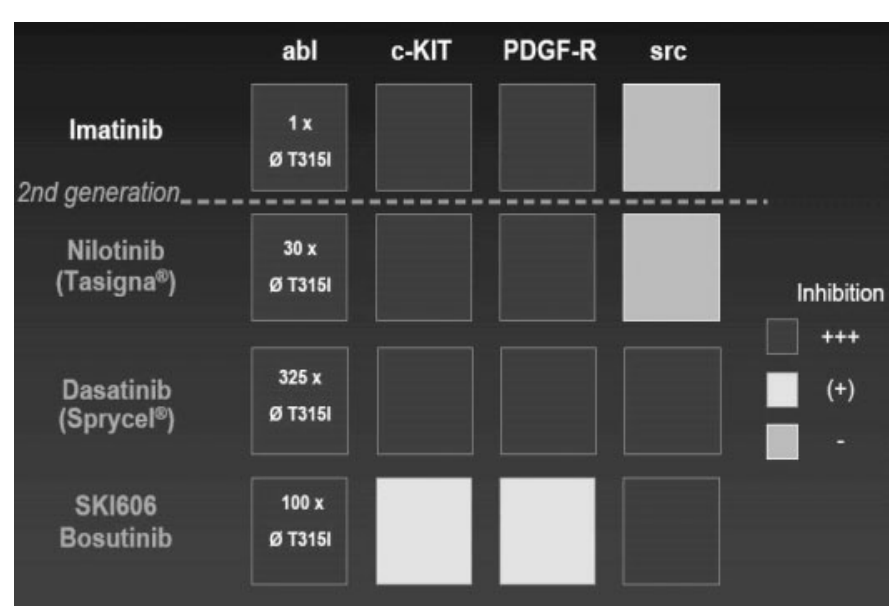

Fig. 3. Targets of different tyrosine kinase inhibitors used for treatment of CML patients.

international laboratories, an international scale on which the standardized 'baseline' as established in the IRIS trial is taken to represent $100 \%$, has been recommended, and a 3-log reduction from the standardized baseline (MMR) is fixed at $0.1 \%$ [21]. In order to determine the international scale con-
Table 4. Operational definitions of failure and suboptimal response for chronic phase CML patients following imatinib therapy (400 g/day)

\begin{tabular}{l} 
Imatinib failure \\
\hline No hematologic remission after 3 months \\
No complete hematologic remission or no cytogenetic remission after \\
6 months \\
No cytogenetic remission (complete or partial) after 12 months \\
Loss of hematologic and/or cytogenetic remission (any time) \\
Suboptimal response
\end{tabular}

No complete hematologic remission after 3 months

No partial cytogenetic remission after 6 months

No complete cytogenetic remission after 12 months

Less than molecular remission after 18 months

Loss of molecular remission (any time)

\section{Warnings}

High risk, del9q+, additional chromosomal abnormalities in $\mathrm{Ph}+$ cells (time of diagnosis)

No major molecular remission after 12 months

Any rise in transcript level (bcr-abl/abl ratio), other chromosomal

abnormalities in $\mathrm{Ph}+$ cells (any time)

Increase of bcr-abl transcripts (1-log) (any time)

version factor $(\mathrm{CF})$ for each laboratory, RT-PCR values must be referenced to a set of verified samples of known value (e.g. plasmids, cell extracts, stabilized RNA). The CF is then derived from the ratio between the value that represents a major molecular response (MMR) on the international scale and the laboratory bcr-abl/control gene $\%$ value that is equivalent to the MMR value as established in the IRIS trial. Bcr-abl values of each laboratory are multiplied by the CF to obtain the corresponding bcr-abl levels on the international scale [21].

Molecular responses monitored by RT-PCR have important clinical implications. At the individual level, RT-PCR studies can identify the degree of molecular response that predicts long-term stability and patterns of response that indicate relapse and imatinib resistance. Achieving an MMR (standardized ratio $<0.1 \%$ ) after 12 months of therapy is associated with prolonged remission and a significantly better probability of relapse-free survival [22]. In contrast, increasing levels of bcr-abl transcripts may be associated with the presence of point mutations in the kinase domain of the bcr-abl protein. The detection of bcr-abl point mutations ('mutation analysis') is recommended in any case of treatment failure or suboptimal response, including a confirmed (significant) rise of bcrabl transcript levels. There is currently no clear evidence that a chronic phase CML patient defined as high risk (Sokal or Hasford criteria) is also at high risk for developing point mutations. However, for chronic phase patients who start treatment with imatinib, mutation screening is indicated if there is 
Table 5. Small molecules for treatment of CML patients under preclinical and clinical development (examples)

\begin{tabular}{llll}
\hline Drug & Target molecule & $\begin{array}{l}\text { T315I } \\
\text { mutation } \\
\text { activity }\end{array}$ & Development status \\
\hline Imatinib (Glivec $\left.^{\circledR}\right)$ & bcr/abl, c-kit, PDGF-R & no & approved (1st line) \\
Dasatinib (Sprycel $\left.^{\circledR}\right)$ & bcr/abl, c-kit, PDGF-R, src & no & approved (2nd line) \\
Nilotinib (Tasigna $\left.^{\circledR}\right)$ & bcr/abl, c-kit, PDGF-R & no & approval expected in 2007 \\
Bosutinib (SKI-606) & bcr/abl, src & no & phase II \\
INNO-406 (NS-187) & bcr/abl, Lyn & no & phase I \\
MK-0457 (VX-680) & Aurora A, B, C; bcr/abl, Flt-3 & yes & phase I/II \\
PHA-739358 & Aurora A, B, C & yes & phase II \\
AS 703569 & Aurora A, B, C & yes & phase I \\
IPI-504 (17-AAG) & HSP-90 & yes & phase I \\
XL 228 & bcr/abl, src, IGF-1-R & yes & phase I planned \\
ON012380 & bcr/abl, PDGF-R, src, (c-kit) & yes & phase I planned \\
SGX-70430 & bcr/abl & yes & preclinical \\
BIRB-796 & bcr/abl, p38 MAP-Kinase & yes & preclinical \\
AP23464 & bcr/abl, src, c-kit & yes & preclinical \\
\hline
\end{tabular}

inadequate initial response or any sign of loss of response (increase in bcr-abl/abl ratio; fig. 2 and [12]). In advanced phase CML patients, again mutation analysis is not indicated before starting imatinib treatment. However, mutation screening is to be performed in such patients if they fail to respond to imatinib, or if, having responded, they subsequently have rising numbers of bcr-abl transcripts.

In the case of suboptimal response (definitions see table 4), the first choice of treatment should be dose escalation of imatinib (600-800 mg/day), provided that the patient tolerated the initial dose of $400 \mathrm{mg}$ and mutation analyses revealed no bcrabl mutation with a high level of imatinib resistance. In patients who failed imatinib therapy (400 mg/day) (definitions see table 4 ), dose escalation ( $800 \mathrm{mg} /$ day) should only be taken into account if resistance to imatinib was not associated with a mutation conferring imatinib resistance. If in both cases mutations which are not sensitive to imatinib are detected or the patients are not eligible for imatinib dose escalation, imatinib therapy has to be discontinued, and patients should be switched to a second line tyrosine kinase inhibitor (e.g. dasatinib (Sprycel ${ }^{\circledR}$, Bristol-Myers Squibb, Munich, Germany; FDA and EMEA approved), or other experimental drugs). Alternatively, allogeneic SCT could be offered to patients if a suitable donor is available. Resistance to imatinib (400-600mg/day) is a well-recognized problem for CML patients, and escalating the imatinib dose to $800 \mathrm{mg} /$ day can overcome some of these cases, but the resulting responses are short in duration and tolerability of high-dose imatinib continues to be an issue. In a recently published phase II study [23] patients with imatinib-resistant chronic phase CML were randomized 2:1 to $140 \mathrm{mg}$ dasatinib $(\mathrm{n}=101)$ or $800 \mathrm{mg}$ imatinib $(\mathrm{n}=49)$. With a medium follow-up of 15 months, complete hematologic responses were observed in 93 and $82 \%$ of patients receiving dasatinib and high-dose imatinib $(p=0.034)$, respectively. Furthermore, dasatinib resulted in higher major cytogenetic response rates $(52 \%)$ than high-dose imatinib $(33 \%, p=0.023)$ including complete cytogenetic responses $(40$ vs. $10 \%, p=0.004)$, suggesting that dasatinib appears to be more active than high-dose imatinib in patients who experience imatinib failure. In patients presenting with warning features (definitions see table 4), standard treatment is still imatinib (400 mg/day), but any warning should alert to the possibility that the patient might become eligible for imatinib dose escalation (600-800 mg/day), allogeneic SCT, or for second line tyrosine kinase inhibitors (or other investigational drugs). By minimizing susceptibility to drug-resistant kinase domain point mutations in preclinical studies, dasatinib, nilotinib (Tasigna ${ }^{\circledR}$, Novartis, Basel, Switzerland) and other compounds represent important advances in CML targeted therapy (reviewed by [24]; fig. 3). The early successes of these compounds suggest that the majority of patients with imatinib-resistant chronic phase disease will achieve objective responses, but the durability of responses with theses agents remains to be defined. Clearly, the T315I mutation ('gatekeeper mutation') represents an important gap in the coverage of dasatinib and nilotinib, and it is possible that the majority of acquired resistance to these compounds will be mediated by selective outgrowth of cells harboring this mutation. To date, the only established therapeutic option for patients with the T315I mutation is SCT [25]. If SCT is not applicable, hydroxyurea, homoharringtonine, or experimental drugs (e.g. MK-0457) may be therapeutic alternatives. Although a couple of new compounds have shown activity against T315I bcr-abl in preclinical systems (table 5), recent work in clinical studies has shown that the Aurora kinase inhibitor MK-0457 (VX-680) can induce objective clinical responses in patients with T315I phenotype refractory CML [26]. In addition, PHA-739358 (Nerviano Medical Science, Milano, Italy), an orally bio-available inhibitor of Aurora kinases A, B, and C, has shown potent anti-proliferative activity in CML cell lines harboring the 
T315I mutation [7]. Following successful phase I clinical trials, this compound is currently being studied in a phase II trial in CML patients who have relapsed after imatinib therapy. While these results are encouraging, it mains to be determined whether Aurora kinase inhibitors will be tolerated in patients or have their own distinct set of resistance mutations, and highlights the need for clinical-grade inhibitors against the T315I mutation. Therefore, strategies to override resistance mediated by the T315I mutation represent the next major frontier in the targeted treatment of CML and may help to improve survival in accelerated and blast phase patients.

\section{Acknowledgement}

The authors thank Professor Andreas Hochhaus (Mannheim) for critical reading of the manuscript.

\section{References}

1 Quintas-Cardama A, Cortes JE: Chronic myeloid leukemia: diagnosis and treatment. Mayo Clin Proc 2006;81:973-988

2 Druker BJ, Guilhot F, O'Brian SG, Gathmann I, Kantarjian H, Gattermann N, et al.: Five-year follow-up of patients receiving imatinib for chronic myeloid leukemia. N Engl J Med 2006;355: 2408-2417.

3 Cortes J, O'Brian S, Kantarjian H: Discontinuation of imatinib therapy after achieving a molecular response. Blood 2004;104:2204-2205.

4 Rousselot P, Huguet F, Rea D, et al.: Imatinib mesylate discontinuation in patients with chronic myelogenous leukemia in complete molecular remission for more than 2 years. Blood 2007;109: $58-60$.

5 Lahaye T, Riehm B, Berger U, et al.: Response and resistance in 300 patients with bcr-abl-positive leukemias treated with imatinib in a single center. A 4.5-year follow-up. Cancer 2005;103:1659-1669.

6 Mahon FX, Deininger MW, Schultheis B, et al.: Selection and characterization of bcr-abl positive cell lines with differential sensitivity to the tyrosine kinase inhibitor STI571: diverse mechanisms of resistance. Blood 2000;96:1070-1079.

7 Weisberg E, Manley PW, Cowan-Jacob SW, et al.: Second generation inhibitors of bcr-abl for the treatment of imatinib-resistant chronic myeloid leukaemia. Nat Rev Cancer 2007;7:345-356.

8 Melo JV, Chuah C: Resistance to imatinib mesylate in chronic myeloid leukaemia. Cancer Lett 2007; 249:121-132.

9 Soverini S, Colarossi S, Gnani A, et al.: Contribution of abl kinase domain mutations to imatinib resistance in different subsets of Philadelphia-positive patients: by the GIMEMA Working Party on Chronic Myeloid Leukemia. Clin Cancer Res 2006; 12:7374-7379.
10 Branford S, Rudzki Z, Walsh S, et al.: Detection of bcr-abl mutations in patients with CML treated with imatinib is virtually always accompanied by clinical resistance, and mutations in the ATP phosphate-binding loop (P-loop) are associated with a poor prognosis. Blood 2003;102:276-283.

11 Shah N, Skaggs B, Branford S, et al.: Sequential kinase inhibitor therapy in CML patients can select for cells harbouring compound bcr.abl kinase domain mutations with increased oncogenic potency: rationale for early combination therapy of abl kinase inhibitors. Blood 108;2006:225a-226a.

12 Baccarani M, Saglio G, Goldman J, et al.: Evolving concepts in the management of chronic myeloid leukemia: recommendations from an expert panel on behalf of the European LeukemiaNet. Blood 2006;108:1809-1820.

13 Donato NJ, Wu JY, Stapley G, et al.: BCR-ABL independence and LYN kinase overexpression in chronic myelogenous leukemia cells selected for resistance to STI571. Blood 2003;101:690-698.

14 Hochhaus A, Erben P, Ernst T, Mueller MC: Resistance to targeted therapy in chronic myelogenous leukemia. Semin Hematol 2007;44(suppl 1):15-24.

15 Gambacorti-Passerini C, Barni, R, Le Coutre P, et al.: Role of alpha1 acid glycoprotein in the in vivo resistance of human bcr/abl(+) leukemic cells to the abl inhibitor STI571. J Natl Cancer Inst 2000;92: $1641-1650$.

16 Thomas J, Wang L, Clark RE, et al.: Active transport of imatinib into and out of cells: implications for drug resistance. Blood 2004;104:3739-3745.

17 Mahon FX, Belloc F, Lagarde V, et al.: MDR1 gene overexpression confers resistance to imatinib in leukemia cell line models. Blood 2003;101: 2368-2373.

18 Burger H, van Tol H, Brok M, et al.: Chronic imatinib mesylate exposure leads to reduced intracellular drug accumulation by induction of the ABCG2 (BCRP) and ABCB1 (MDR1) drug transport pumps. Cancer Biother 2005;4:747-752.
19 Crossman LC, Druker BJ, Deininger MW, et al.: hOCT 1 and resistance to imatinib. Blood 2005; 106:1133-1134.

20 Sleijfer S, Wiemer E, Seynaeve C, Verweij J: Improved insight into resistance mechanisms to imatinib in gastrointestinal stromal tumors: a basis for novel approaches and individualization of treatment. Oncologist 2007;12:719-726.

21 Hughes TP, Deininger M, Hochhaus A, Branford S, Radlich J, Kaeda J, Baccarani M, Cortes J, Cross NC, Druker BJ, Gabert J, Grimwade D, Hehlmann R, Kamel-Reid S, Lipton JH, Longtine J, Martinelli G, Saglio G, Soverini S, Stock W, Goldman JM: Monitoring CML patients responding to treatment with tyrosine kinase inhibitors: review and recommendations for harmonizing current methodology for detecting BCR-ABL transcripts and kinase domain mutations and for expressing results. Blood 2006;108:28-37.

22 Iacobucci I, Saglio G, Rosti G, et al.: Achieving a major molecular response in at the time of a complete cytogenetic response $(\mathrm{CCgR})$ predicts a better duration of $\mathrm{CCgR}$ in imatinib treated chronic myeloid leukaemia patients. Clin Cancer Res 2006; 12:3037-3042.

23 Kantarjian H, Pasquini R, Hamerschlak N, et al. Dasatinib or high-dose imatinib for chronic-phase chronic myeloid leukemia after failure of first-line imatinib: a randomized phase 2 trial. Blood 2007; 109:5143-5150.

24 Burgess MR, Sawyers CL: Treating imatinib-resistant leukemia: the next generation targeted therapies. ScientificWorldJournal 2006;6:918-930.

25 O'Hare T, Corbin AS, Druker BJ: Targeted CML therapy: controlling drug resistance, seeking cure. Curr Opin Genet Dev 2006;16:92-99.

26 Giles F, Cortes J, Jones D, Bergstrom D, Kantarjian H, Freedman SJ: MK-0457, a novel kinase inhibitor, is active in patients with chronic myeloid leukemia or acute lymphocytic leukemia with the T315I BCR-ABL mutation. Blood 2007;109: 500-502. 